\title{
Prevalence, Impact, and Management Practice of Dysmenorrhea among University of Gondar Students, Northwestern Ethiopia: A Cross-Sectional Study
}

\author{
Minaleshewa Biruk Gebeyehu, ${ }^{1}$ Abebe Basazn Mekuria, ${ }^{2}$ \\ Yonas Getaye Tefera, ${ }^{1}$ Dagmawi Abate Andarge, ${ }^{1}$ Yabsira Belayneh Debay, ${ }^{1}$ \\ Geremew Sokile Bejiga, ${ }^{1}$ and Begashaw Melaku Gebresillassie ${ }^{1}$ \\ ${ }^{1}$ Department of Clinical Pharmacy, School of Pharmacy, University of Gondar, Gondar, Ethiopia \\ ${ }^{2}$ Department of Pharmacology, School of Pharmacy, University of Gondar, Gondar, Ethiopia
}

Correspondence should be addressed to Begashaw Melaku Gebresillassie; begashaw531@gmail.com

Received 15 January 2017; Revised 15 March 2017; Accepted 6 April 2017; Published 14 May 2017

Academic Editor: Hind A. Beydoun

Copyright (C) 2017 Minaleshewa Biruk Gebeyehu et al. This is an open access article distributed under the Creative Commons Attribution License, which permits unrestricted use, distribution, and reproduction in any medium, provided the original work is properly cited.

\begin{abstract}
Background. Dysmenorrhea is an important health problem of adolescents in school, as well as health practitioners, that badly affects the daily activities and quality of life. The aim of this study was to measure the prevalence of dysmenorrhea and assess its management practice among University of Gondar students. Methods. A cross-sectional study was done from April 06 to May 08, 2016, on female students of University of Gondar. Descriptive and binary logistic regression analyses were used to describe and assess the association between different variables. Results. More than two-thirds $(75.3 \%)$ of the respondents were nonmedical students and the prevalence of dysmenorrhea was $77.6 \%$. About half $(50.6 \%)$ of the participants reported that they have a family history of dysmenorrhea and experienced continuous type of pain (53\%) which lasts 1-2 days (47.8\%). Abdominal spasm (70.4\%), back pain $(69.7 \%)$ fatigue, and weakness $(63.5 \%)$ were the most commonly experienced dysmenorrhea symptoms. More than half (63\%) of the respondents had encountered social withdrawal and decrease in academic performance (51.4\%). More than twothirds $(63.8 \%)$ of the respondents use home remedies as a primary management option. Ibuprofen and diclofenac were the most commonly used medications to manage dysmenorrhea. Conclusions. The present study revealed that high proportion of University of Gondar female students had dysmenorrhea. Findings suggest the need for educating adolescent girls on appropriate and effective management of dysmenorrhea.
\end{abstract}

\section{Introduction}

Menstrual period is a natural phenomenon which occurs throughout the reproductive years of every woman. Most females experience certain degree of pain and distress during their menstruation period [1]. Dysmenorrhea is a painful/cramping sensation in the lower abdomen often accompanied by other biological symptoms including dizziness, fatigue, sweating, backache, headache, nausea, vomiting, and diarrhea all occurring just before or during the menstruation.

Dysmenorrhea may be categorized into two types as primary and secondary. Primary dysmenorrhea is defined as painful menses among females with normal pelvic anatomy, frequently beginning during adolescence. It is observed only in ovulatory cycles, frequently emerging within 6 to 12 months after menarche with no pathology or organic basis. Secondary dysmenorrhea is a menstrual pain associated with underlying pathology and its onset might be years after menarche [2]

Due to its importance, different treatments including pharmacological and nonpharmacological treatment approaches such as taking nonsteroidal anti-inflammatory drugs (NSAIDS), herbal, dietary therapies, yoga, meditation, and acupuncture have been used to lessen the effects of dysmenorrhea [3]. 
According to Ethiopian standard treatment guideline, dysmenorrhea occurs in about $50 \%$ of menstruating women. Dysmenorrhea in some years following menarche is usually primary, but the secondary characteristically occurs many years after menarche.

Primary dysmenorrhea is extremely common, especially among adolescents. As many as $90 \%$ of adolescent females and above $50 \%$ of menstruating women worldwide report suffering from it, with $10-20 \%$ of them describing their hurt as severe and distressing [4].

Dysmenorrhea is a cause of frequent short-term work and school absenteeism in women of reproductive age. Approximately $10-15 \%$ of females experience monthly menstrual pain severe enough to stop normal daily functions at work, home, or school [2].

Even though primary dysmenorrhea is not a real threat of life but can affect the quality of females' life and in case of severity it might lead to disability and inefficiency. Moreover, dysmenorrhea can cause mental problems in some of the females resulting in their loneliness and reduced participation in different social activities.

In adolescents, moderate to severe pain that affects lifestyle and does not respond to pharmacological treatment requires professional attention and appropriate diagnosis of possible underlying pelvic disease. The exact prevalence of dysmenorrhea is difficult to determine because of variety of diagnostic criteria and the subjective feature of the symptoms. In many countries, primary dysmenorrhea is the principal cause of recurrent short-term work and school absenteeism in young girls and women [3].

We could not found a study which was done on the prevalence and management of dysmenorrhea and this study has significant importance to determine and explore the prevalence, impact, and treatment practice of dysmenorrhea. Moreover, the findings might have significant impact in decreasing risks associated with self-management of dysmenorrhea.

\section{Materials and Methods}

2.1. Study Setting and Period. An institution-based crosssectional study was employed to assess the prevalence, impact, and management practice of dysmenorrhea among female students of University of Gondar (UOG) from April 06-May 08, 2016. UOG is one of the oldest and most well established higher education institutions in the country and located $738 \mathrm{~km}$ northwest of Addis Ababa which is a capital city of Ethiopia. It has five campuses, namely, Maraki, Atse Tewodros, Atse Fasil, College of Medicine and Health Sciences (CMHS), and Meles Zenawi. Currently, through nine academic units; College of Medicine and Health Sciences, Business and Economics, Natural and Computational Sciences, and Social Sciences and Humanities; Faculty of Veterinary Medicine and Agriculture; Schools of Law, Technology, and Education, it offers 64 postgraduate and 56 undergraduate programs in regular, extension, summer, and distance programs.
2.2. Study Population. The source population includes all female students currently learning at University of Gondar, whereas the study population includes female students who were available during the data collection period.

2.3. Sample Size Determination and Sampling Procedure. The sample size was calculated using a single mean formula [5]:

$$
n=\frac{z^{2} p(1-p)}{d^{2}}
$$

where $n$ is the sample size required; $d$ is marginal error of $5 \%(d=0.05) ; z$ is the degree of accuracy required at $95 \%$ confidence level $=1.96$; $p$ is the proportion of dysmenorrhea occurrence among female University of Gondar students $(0.5$ [50\%]).

Using the aforementioned formula,

$$
\begin{aligned}
n i & =\frac{(1.96)^{2}(0.5)(1-0.5)}{(0.05)^{2}}=\frac{(3.8416)(0.25)}{0.0025} \\
& =\frac{0.9604}{0.0025}=385 .
\end{aligned}
$$

Since the sample was taken from source population of 6211 female students, which is $<10,000$, the final sample size was calculated after using correction factor:

$$
\begin{aligned}
& n f=\frac{n i}{1+n i / N}, \\
& n f=\frac{385}{1}+\frac{385}{6211}=\frac{385}{1.0619}=362 .
\end{aligned}
$$

After $10 \%$ of the calculated sample size was added for possible nonresponse, the final sample size became 400 female students.

Out of 6211 female students currently learning at University of Gondar, 400 students from all five campuses were drawn by employing stratified and simple random sampling technique. The required number of samples from each campus was determined by multiplying the ratio of total female students in each campus to total number of female students in the university (6211) with the calculated final sample size (400). Following determination of number of samples to be taken from each campus, using simple random sampling technique, the required samples were selected (Figure 1).

2.4. Study Variables. The independent variables include age, sex, family history, ethnicity, monthly income, knowledge, duration of menarche, and menstrual irregularity. The dependent variables were the prevalence, impact, and management practice of dysmenorrhea.

2.5. Data Collection and Management. The data collection tool used in the study was adopted from previous studies and prepared in English. This was translated to Amharic local language and then back to English in order to ensure that the translated version gives proper meaning. The questionnaire has three major parts which focused on sociodemographic 


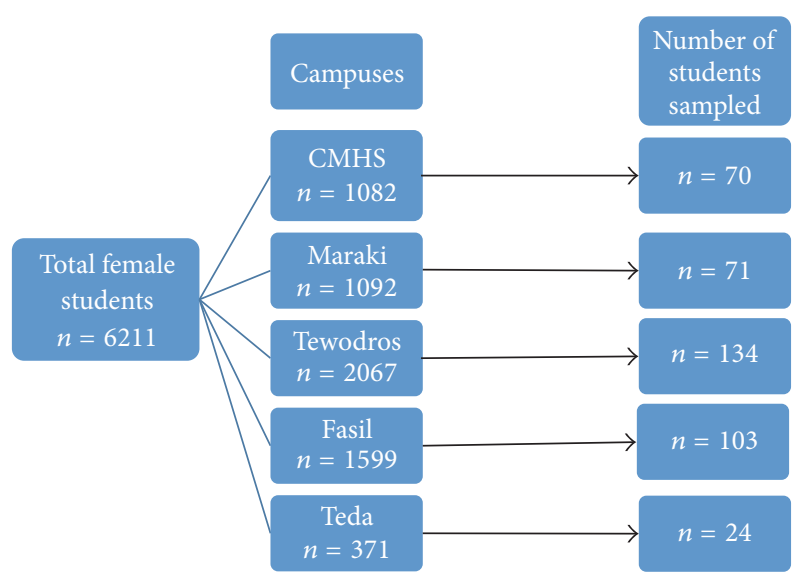

FIGURE 1: Flowchart of sampling procedure (selected from each campus using simple random sampling technique).

characteristics, menstruation characteristics and its impact, and management practice of dysmenorrhea. The data collection instrument was pretested on 20 students who were not included in the final analysis and relevant modifications were instituted before the commencement of actual data collection. The data were collected by eight principal investigators through interviewer-administered questionnaires and faceto-face interview by explaining the questions for those who were unable to understand. The investigators who collected the data were properly trained on the instrument and ways of approaching the students and securing their permission for interview prior to the data collection process.

2.6. Data Entry and Analysis. The collected data using quantitative method were cleaned, entered into, and analyzed using IBM SPSS version 20.0. In the study, sociodemographic characteristics, prevalence, impact, and management practice of dysmenorrhea were described using frequencies, percentage, and mean and standard deviation. Binary logistic regression analysis was employed to determine the association between different variables, and $P$ values less than 0.05 and 95\% confidence interval (CI) were used as cutoff points for determining statistical significance of associations among different variables.

2.7. Ethical Consideration. This study was conducted after ethical clearance was gained from research and ethics review committee of School of Pharmacy. Verbal informed consent was obtained and each of the participants was provided with explanations on the purpose of the study. They were also informed that participation was voluntary and they could withdraw from the study at any stage if they desired.

2.8. Operational Definitions. Home remedies included coffee, tea, coca, cold bath, massage, heat compression, and their combination.

Nondrug users are participants who do not use medication for their dysmenorrheal pain.

Antipyretic that was used is paracetamol.

NSAIDS that were used are ibuprofen and diclofenac.

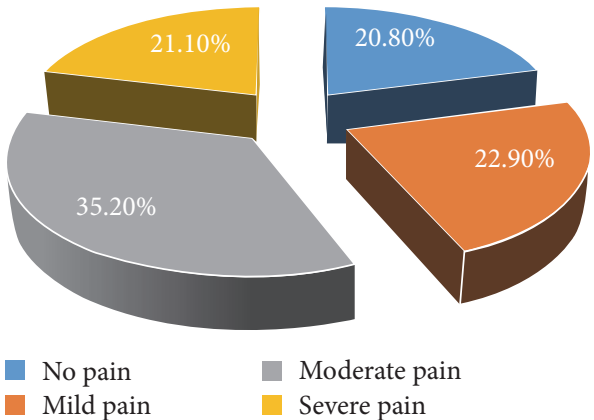

FIGURE 2: Degree of pain among female students of UOG, Gondar, 2016.

Opioids that were used included tramadol.

Contraceptives that were used were oral contraceptive pills.

\section{Results}

3.1. Sociodemographic Characteristics of Respondents. In this study, out of the total interview guides/questionnaires of sample of 400 students who were interviewed, 389 were included in the analysis and 11 encounters were excluded due to incompleteness making the response rate $97.3 \%$. The average age of study respondents was 21 years. More than two-thirds (75.3\%) of the study participants were nonmedical students and age at which they started menstruating was 12-14 years. About half $(50.6 \%)$ of the respondents reported that they have a family history of dysmenorrhea and the pain starts to occur at the time of menstruation for $45.5 \%$ of the respondents (Figure 4). Along with this, about (35.2\%) experienced moderate and continuous type of pain $(53 \%)$ which lasts for 1-2 days (47.8\%) (Figure 2). In more than twothirds (62.\%) of the respondents, their menstruation cycle length ranged within 26-30 days with the duration of flow being 3-4 days (Figure 3 ). The most frequently experienced dysmenorrhea symptoms reported were abdominal spasm (70.4\%), back pain (69.7\%) fatigue, and weakness (63.5\%), respectively (Table 1 ).

3.2. Impact and Management Practice of Dysmenorrhea. More than two-thirds (63\%) of the respondents reported that they had encountered social withdrawal and decrease in academic performance (51.4\%). More than one-third (40.9\%) of the respondents experienced restrictions from day-today activities during their menstrual period and associated with this about $31.1 \%$ were absent from class and reported poor concentration (43.4\%). Nearly half $(42.7 \%)$ of the respondents reported they had decreased appetite and altered sleeping pattern.

Out of all the respondents, only $8 \%$ of them performed physical exercises and about two-thirds (60.9\%) of them were using home remedies as a nonpharmacological treatment option of dysmenorrhea, whereas only $16.2 \%$ the respondents consult health professionals about their dysmenorrheal condition. About $36.3 \%$ of them were using medications to manage their dysmenorrheal pain and ibuprofen 
TABLE 1: Sociodemographic and menstrual characteristics of respondents, Gondar, 2016.

\begin{tabular}{|c|c|c|}
\hline Variables & Frequency & Percent \\
\hline \multicolumn{3}{|l|}{ Year of study } \\
\hline First & 114 & 29.3 \\
\hline Second & 137 & 35.2 \\
\hline Third & 77 & 19.8 \\
\hline Fourth & 42 & 10.8 \\
\hline Fifth & 16 & 4.1 \\
\hline Sixth & 3 & 0.8 \\
\hline \multicolumn{3}{|c|}{ Religion of the respondents } \\
\hline Muslim & 21 & 5.4 \\
\hline Protestant & 52 & 13.4 \\
\hline Catholic & 2 & 0.5 \\
\hline Orthodox & 313 & 80.5 \\
\hline \multicolumn{3}{|l|}{ Family income } \\
\hline$<500$ & 128 & 32.9 \\
\hline $500-1000$ & 177 & 45.5 \\
\hline $1001-2000$ & 78 & 20.1 \\
\hline$>2000$ & 6 & 1.5 \\
\hline \multicolumn{3}{|l|}{ Faculty } \\
\hline Medical & 96 & 24.7 \\
\hline Nonmedical & 293 & 75.3 \\
\hline \multicolumn{3}{|l|}{ Age at menarche } \\
\hline $9-11$ years & 22 & 5.7 \\
\hline $12-14$ years & 230 & 59.1 \\
\hline $15-17$ years & 137 & 35.2 \\
\hline \multicolumn{3}{|c|}{ Experience dysmenorrhea? } \\
\hline Yes & 302 & 76.6 \\
\hline No & 87 & 24.4 \\
\hline \multicolumn{3}{|c|}{ Family history of dysmenorrhea } \\
\hline Yes & 197 & 50.6 \\
\hline No & 192 & 49.4 \\
\hline \multicolumn{3}{|c|}{ Duration of bleeding } \\
\hline $1-2$ days & 186 & 47.8 \\
\hline 3-4 day & 96 & 24.7 \\
\hline 5 and more days & 31 & 8.0 \\
\hline \multicolumn{3}{|l|}{ Type of pain } \\
\hline Continuous pain & 108 & $27.8 \%$ \\
\hline Intermittent pain & 206 & $53 \%$ \\
\hline
\end{tabular}

(12.6\%), diclofenac (6.9\%), and paracetamol (5.4\%) were the most frequently used medications, whereas coffee, tea, and Coca-Cola $(34.4 \%)$, and heat therapy $(3.9 \%)$ were among the most frequently used home remedies to manage their illness.

Out of those respondents who were using medications, the majority $(82.3 \%)$ of them took their medications at the time of menses (75.9\%) 1-2 times per day in PO rout of administration (89.4\%) for 1-2 days (61\%) (Table 2).

3.3. Respondents' Knowledge about Medication. In this study, out of 389 respondents, only $15.4 \%$ and $12.6 \%$ of them knew about the precautions and warnings and contraindications of the drugs they were taking, respectively. Regarding dosage of the medications, only $17.7 \%$ knew the recommended maximum daily dose of the drugs. Along with this, also only $12.6 \%$ of the respondents knew contraindications of the drugs they were taking to manage their pain. Similarly, the majority of the respondents did not know about the adverse effect associated with the drugs they were taking (Table 2).

3.4. Predictors of Dysmenorrhea, Medication, and Home Remedy Use. In logistic regression analysis, family history of dysmenorrhea and duration of menstrual blood flow were found to have independent determining factors for the probability of dysmenorrhea to occur. Students with five and more days of menstrual blood flow $(\mathrm{AOR}=0.292,95 \% \mathrm{CI}=$ 
TABLE 2: Types of medications used, knowledge about drugs, and medication practice of the respondents, Gondar, 2016.

\begin{tabular}{|c|c|c|}
\hline Type of drugs used & Frequency & Percent \\
\hline Nondrug users & 248 & 63.8 \\
\hline Antipyretic & 21 & 5.4 \\
\hline NSAIDS & 91 & 23.4 \\
\hline Opioids & 3 & .8 \\
\hline Contraceptives & 5 & 1.3 \\
\hline Antipyretic, NSAIDS, opioids, and oral contraceptives & 3 & 8 \\
\hline NSAIDS and opioids & 6 & 6 \\
\hline Antipyretic and NSAIDS & 7 & 9 \\
\hline NSAIDS and contraceptives & 3 & .8 \\
\hline Antipyretic, NSAIDS, and opioids & 2 & 5 \\
\hline \multicolumn{3}{|l|}{ Route of administration } \\
\hline Nondrug users & 248 & 63.8 \\
\hline $\mathrm{PO}$ route & 126 & 32.4 \\
\hline IM (IV) route & 7 & 1.8 \\
\hline PO and IM (IV) & 8 & 2.1 \\
\hline \multicolumn{3}{|l|}{ Frequency of drug used per day } \\
\hline Nondrug users & 248 & 63.8 \\
\hline 1-2 times per day & 116 & 29.8 \\
\hline 3-4 times per day & 8 & 2.1 \\
\hline PRN (when needed) & 17 & 4.4 \\
\hline \multicolumn{3}{|l|}{ Initiation of medications } \\
\hline Nondrug users & 248 & 63.8 \\
\hline One week prior to menarche & 6 & 1.5 \\
\hline 2-3 days before menses & 16 & 4.1 \\
\hline At menarche & 107 & 27.5 \\
\hline After menarche & 12 & 3.1 \\
\hline \multicolumn{3}{|l|}{ Duration of drug use } \\
\hline Nondrug users & 248 & 63.8 \\
\hline 1-2 days & 86 & 22.1 \\
\hline 3-4 days & 13 & 3.3 \\
\hline PRN (when needed) & 42 & 10.8 \\
\hline \multicolumn{3}{|l|}{ Knowledge on the precaution/warning of the drug used } \\
\hline Yes & 60 & 15.4 \\
\hline No & 329 & 84.6 \\
\hline \multicolumn{3}{|l|}{ Knowledge on the contraindication of the medication used } \\
\hline Yes & 49 & 12.6 \\
\hline No & 340 & 87.4 \\
\hline \multicolumn{3}{|c|}{ Knowledge on the maximum recommended dose of the drug used } \\
\hline Yes & 69 & 17.7 \\
\hline No & 320 & 82.3 \\
\hline \multicolumn{3}{|l|}{ Knowledge on the risk and adverse effect of the drug used } \\
\hline Yes & 67 & 17.2 \\
\hline No & 322 & 82.8 \\
\hline
\end{tabular}

$0.109-0.783$ ) were found to be $70.8 \%$ less likely not to have dysmenorrhea taking 1-2 days of menstrual blood flow as a reference. On the other hand, being health science students and severity of menstrual pain were statistically significant predictors of medication use. Students from medical (health) faculty $(\mathrm{AOR}=0.228, \mathrm{CI}=0126-0.413$ ) were found to be $77.2 \%$ less likely not to use medications (Table 3 ).

\section{Discussion}

Among the 389 participants, the overall prevalence of dysmenorrhea among University of Gondar students was found to be $77.6 \%$ which was in agreement with the prevalence rate reported by study from Saveetha University, Universitaria Policlinico of Modena, and Private University in Ogun State, 
TABLE 3: Predictors of dysmenorrhea, medication, and home remedy use, Gondar, 2016.

\begin{tabular}{|c|c|c|c|c|c|}
\hline Variables & & & COR $(95 \% \mathrm{CI})$ & $\operatorname{AOR}(95 \% \mathrm{CI})$ & $P$ value \\
\hline \multicolumn{6}{|c|}{ Dysmenorrhea $(n=389)$} \\
\hline & Yes $(\%)$ & No $(\%)$ & & & \\
\hline Family history of dysmenorrhea & & & & & $0.000^{*}$ \\
\hline No & $123(31.6)$ & $69(17.7)$ & 1 & 1 & \\
\hline Yes & $179(46.0)$ & $18(4.6)$ & $0.179(0.102-0.316)$ & $0.192(0.108-0.341)$ & \\
\hline Duration of menstrual flow (bleeding) & & & & & $0.044^{*}$ \\
\hline 1-2 days & $16(4.1)$ & $12(3.1)$ & 1 & 1 & \\
\hline 3-4 days & $197(50.6)$ & $61(15.7)$ & $0.413(0.097-0.683)$ & $0.522(0.224-1.218)$ & \\
\hline 5 and more days & $89(22.9)$ & $14(3.6)$ & $0.210(0.0609-0.321)$ & $0.292(0.109-0.783)$ & \\
\hline \multicolumn{6}{|c|}{ Medication use $(n=389)$} \\
\hline & Yes $(\%)$ & No (\%) & & & \\
\hline Faculty & & & & & $0.000^{*}$ \\
\hline Nonmedical & $89(22.9)$ & $204(52.4)$ & 1 & 1 & \\
\hline Medical (health) & $53(13.6)$ & $43(11.1)$ & $0.354(0.221-0.568)$ & $0.228(0126-0.413)$ & \\
\hline Degree of menstrual pain & & & & & $0.002^{*}$ \\
\hline No pain & $2(0.5)$ & $79(20.3)$ & 1 & 1 & \\
\hline Mild pain & $19(4.9)$ & $70(18.0)$ & $0.093(0.021-0.415)$ & $0.097(0.021-0.439)$ & \\
\hline Moderate pain & $64(16.5)$ & $73(18.8)$ & $0.029(0.007-0.122)$ & $0.025(0.006-0.103)$ & \\
\hline Sever pain & $57(14.7)$ & $25(6.4)$ & $0.011(0.003-0.049)$ & $0.008(0.002-0.038)$ & \\
\hline \multicolumn{6}{|c|}{ Home remedy use } \\
\hline & Yes (\%) & No (\%) & & & \\
\hline Faculty & & & & & 0.510 \\
\hline Nonmedical & $180(46.3)$ & $113(29.0)$ & 1 & 1 & \\
\hline Medical (health) & $57(14.7)$ & $39(10.0)$ & $1.090(0.681-1.744)$ & $1.198(0.700-2.052)$ & \\
\hline Degree of menstrual pain & & & & & $0.000^{*}$ \\
\hline No pain & $13(3.3)$ & $68(17.5)$ & 1 & 1 & \\
\hline Mild pain & $53(13.6)$ & $36(9.3)$ & $0.130(0.063-0269)$ & $0.0128(0.061-0.265)$ & \\
\hline Moderate pain & $101(26)$ & $36(9.3)$ & $0.068(0.034-0.138)$ & $0.067(0.033-0.137)$ & \\
\hline Sever pain & $70(18)$ & $12(3.1)$ & $0.033(0.014-0.077)$ & $0.033(0.014-0.077)$ & \\
\hline
\end{tabular}

${ }^{*} P$ value less than 0.05 .

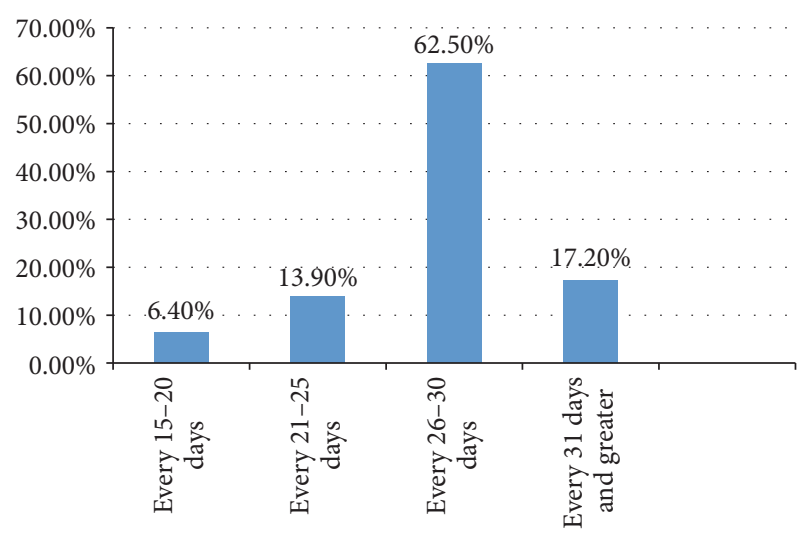

FIGURE 3: Length of menstruation cycle among female students of UOG, Gondar, 2016.

which were $70.6 \%, 84.1 \%$, and $78.1 \%$ for the same question, respectively $[2,6,7]$.
In this study, only $16.2 \%$ of the participants consulted health professionals about their menstrual pain. More than half $(53.7 \%)$ of them endure their pain and only $36.5 \%$ of them uses medication. Regarding these, a similar study done in Nigeria showed that only $7.9 \%$ consulted a healthcare professionals and nearly half (46.3\%) of participants endured dysmenorrhea, along with this only $29.3 \%$ of the participants managed themselves with over-the-counter medications [2]. This might have resulted from variation of baseline knowledge, attitude, and management practice of dysmenorrhea between these population groups.

About half of the students (50.6\%) have family history of dysmenorrhea, out of which about $81.3 \%$ experience pain during their menstruation. This implies that family history and irregular cycle of menstruation can be taken as risk factors to experience dysmenorrhea.

Among the impacts of dysmenorrhea, absenteeism from school, poor concentration, sleep disorder depression, and behavioral change like social withdrawal and restriction from daily activities were the most frequent in this study. 


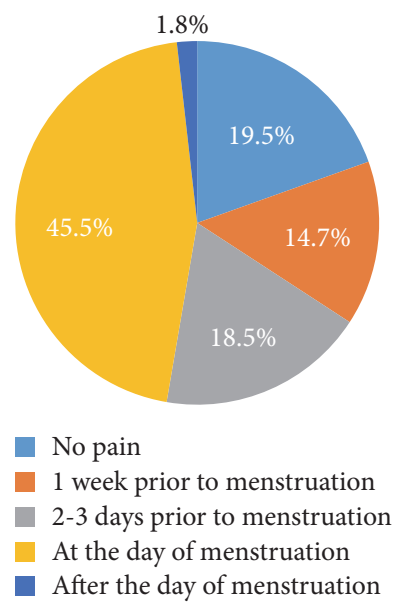

Figure 4: Onset of dysmenorrhea among female students of UOG, Gondar, 2016.

Regarding these, similar results were reported from Nigeria, which shows that there has been an increased number of absenteeism and decreased normal daily functions [2]. These results revealed that during dysmenorrhea students will face a tremendous impact in their educational outcomes and daily activities.

In this study, about $8 \%$ of the students carried out physical exercise as a measure to control their dysmenorrheal illness. Regarding this, a similar study conducted in Iran supports use of physical activity had positive impact on the most of primary dysmenorrhea symptoms $[3,8]$. Unfortunately, none of the respondents from Nigeria reported engaging in physical exercise in order to manage their menstrual pain, rather about $77.2 \%$ restricted physical activity because of the severity of the pain [2].

The present study showed that most of the participants were using home remedies as a nonpharmacologic treatment option for dysmenorrheal pain. As the degree of pain increases, the use of home remedies increases. Along with this, as the pain increases, the students were using more than one type of home remedies at a time. These findings were in agreement with systematic review report from Australia among Chinese, which shows that university students were using Chinese traditional medicine as a nonpharmacological treatment [9].

About $22.9 \%$ of students who were using medications were from nonmedical faculty and they were not aware of the drugs precaution, contraindication, maximum dose, adverse effect, dose, frequency, and duration. This may lead to severe health related complications associated with misuse of drugs. NSAIDs like ibuprofen could result in gastrointestinal bleeding and worsen existing case of peptic ulcer disease [10].

Findings from this study also showed that self-medication practice was higher among students from medical (health) faculty as compared to students from nonmedical faculty. This finding is in contrast with the report from a study conducted in Hong Kong, which showed that more than half of the self-medicated women with dysmenorrhea were particularly nonmedical students [11]. This might be due to lack of medical knowledge associated with the illness and poor access to medications among nonmedical students.

In binary logistic regression analysis, family history and duration of menstrual blood flow were found to have independent determining factors for the probability of dysmenorrhea to occur. Students with five and more days of menstrual blood flow are found to be $70.8 \%$ less likely not to have dysmenorrhea, taking 1-2 days of menstrual blood flow as a reference. On the other hand, being health science students and severity of dysmenorrheal pain were statistically significant predictors of medication use. Students from medical (health) faculty and who have severe pain were more likely to use medications. The possible explanation might be that, among nonmedical students, there was a negative attitude towards dysmenorrhea, as they thought that dysmenorrhea is mostly considered as a normal part of female menstrual cycle and a burden every woman must bear, and knowledge about the available treatment approach is inadequate.

4.1. Limitation of the Study. The participants were selected from only one educational institution which limits the generalizability of the result to other settings. The self-reporting nature of the present study might have resulted in a recall bias and overreporting of the condition. This may have had an impact on the stated prevalence of the illness. Several factors that might affect menstrual outcome were not considered, including smoking, obesity, and stress. This cross-sectional study may serve as an insight for further studies to be conducted on this area that should adopt more rigorous designs to address the issue.

\section{Conclusions}

In this study, the overall prevalence of dysmenorrhea among University of Gondar students was found to be high. About half of the participants stated that they have a family history of dysmenorrhea and the pain starts to occur during the time of menstruation. Along with this, a large number of them experienced moderate and continuous type of pain which lasts for 1-2 days. More than two-thirds of the participants also stated that they had encountered social withdrawal and decrease in academic performance associated with this pain.

About one-third of the participants were using medications to control their dysmenorrheal pain. Along with this, the majority of the participants did not know about the adverse effect associated with the drugs they were taking. In logistic regression analysis, family history, degree of pain, and duration of menstrual blood flow were found to have independent determining factors for the occurrence of dysmenorrhea, home remedy, and medication use. Based on these findings, education on the appropriate management of dysmenorrhea should be given to students, parents, and hostel administrators in order to address the reproductive health needs of the female students.

\section{Abbreviations}

CMHS: College of Medicine and Health Sciences SPSS: Statistical Packages for Social Sciences. 


\section{Conflicts of Interest}

The authors declare that they have no conflicts of interest.

\section{Acknowledgments}

The authors acknowledge the staff and students of University of Gondar for their cooperation during data collection.

\section{References}

[1] S. Kaur, P. Sheoran, and J. Sarin, "Assessment and comparison of dysmenorrhea in terms of severity of pain and utilization of non steroid anti-inflammatory drugs among unmarried and married women," International Journal of Caring Sciences, vol. 8, no. 3, pp. 737-745, 2015.

[2] N. Sharma, M. Sagayaraj, and B. Sujatha, "Menstrual characteristics and prevalence of dysmenorrhea in college students," International Journal of Scientific and Research Publications, vol. 4, no. 10, pp. 1-6, 2014.

[3] N. Mahvash, A. Eidy, and K. Mehdi, "The effect of physical activity on primary dysmenorrhea of female university students," World Applied Sciences Journal, vol. 17, no. 10, pp. 1246-1252, 2012.

[4] K. J. Berkley, "Primary dysmenorrhea: an urgent mandate," International Association for The Study of Pain, vol. 21, no. 3, pp. $1-8,2013$.

[5] S. K. Lwanga and S. Lemeshow, Sample Size Determination for Health Studies: A Practical Manual, World Health Organization, Geneva, Switzerland, 1991, 1-5.

[6] A. A. Farotimi, J. N. Esike, and C. U. Wozichi, "Knowledge, attitude, and healthcare-seeking behavior towards dysmenorrhea among female students of a private university in Ogun state, Nigeria," Journal of Basic and Clinical Reproductive Sciences, vol. 4, no. 1, pp. 33-38, 2015.

[7] G. Grandi, S. Ferrari, A. Xholli et al., "Prevalence of menstrual pain in young women: what is dysmenorrhea?" Journal of Pain Research, vol. 5, pp. 169-174, 2012.

[8] M. Zairian, Z. Abedian, and S. Mazlom, "Self-management in primary dysmenorrhea: toward evidence-based education," Life Science Journal, vol. 8, no. 2, pp. 13-18, 2011.

[9] H. Ju, M. Jones, and G. Mishra, "The prevalence and risk factors of dysmenorrhea," Epidemiologic Reviews Advance Access, vol. 7, no. 3, pp. 1-10, 2013.

[10] J. Marjoribanks, M. Proctor, and C. Farquhar, "Nonsteroidal anti-inflammatory drugs for dysmenorrhea (review)," The Cochrane Library, vol. 1, pp. 1-158, 2010.

[11] C. F. Chia, J. H. Y. Lai, P. K. Cheung et al., "Dysmenorrhoea among Hong Kong university students: prevalence, impact, and management," Hong Kong Medical Journal, vol. 19, no. 3, pp. 222-228, 2013. 


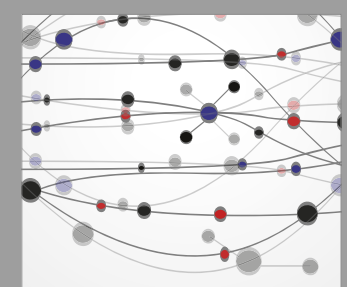

The Scientific World Journal
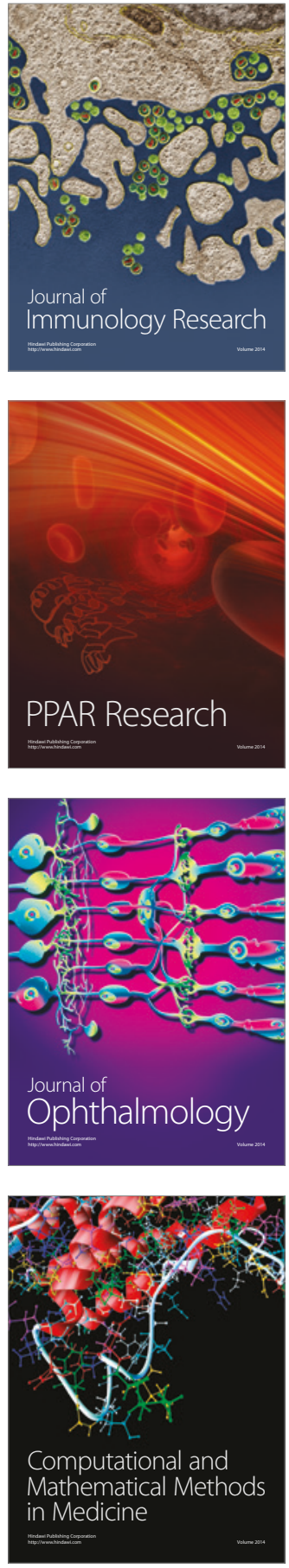

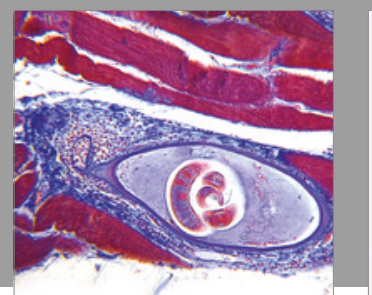

Gastroenterology Research and Practice
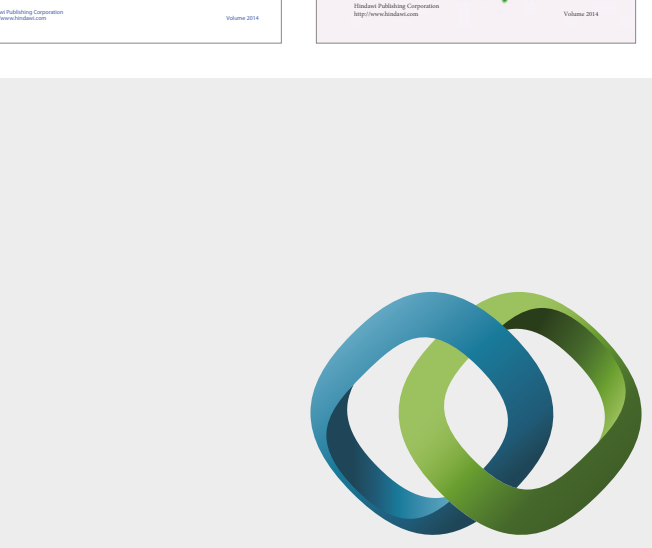

\section{Hindawi}

Submit your manuscripts at

https://www.hindawi.com
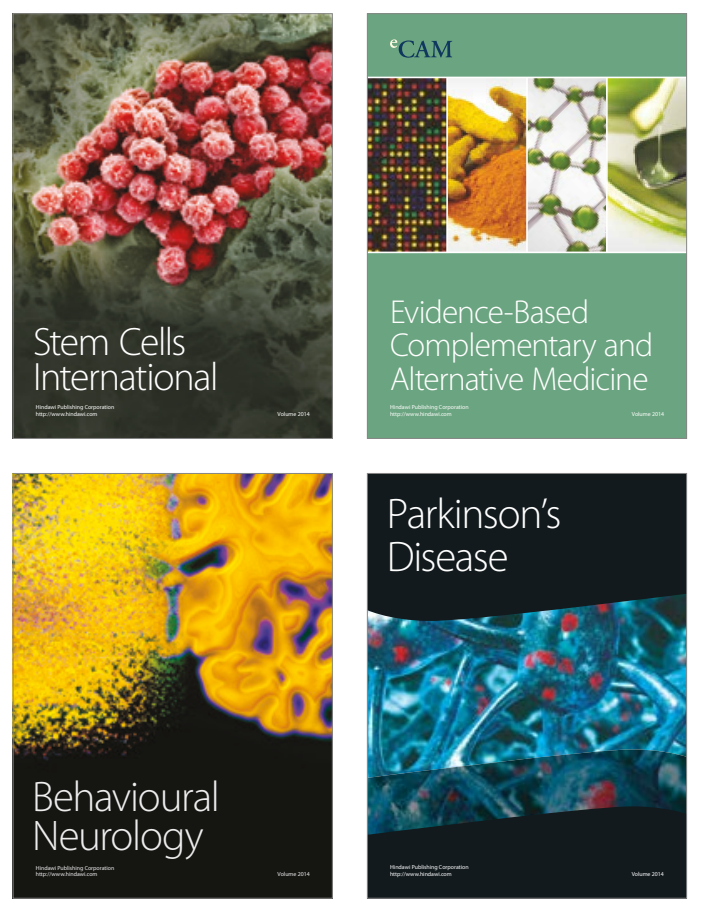
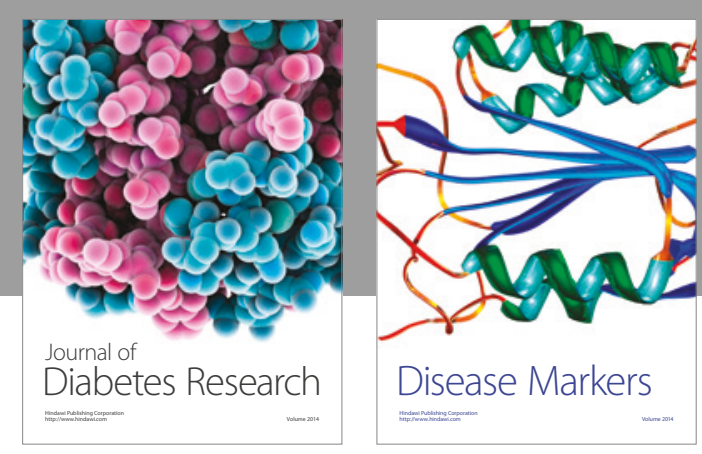

Disease Markers
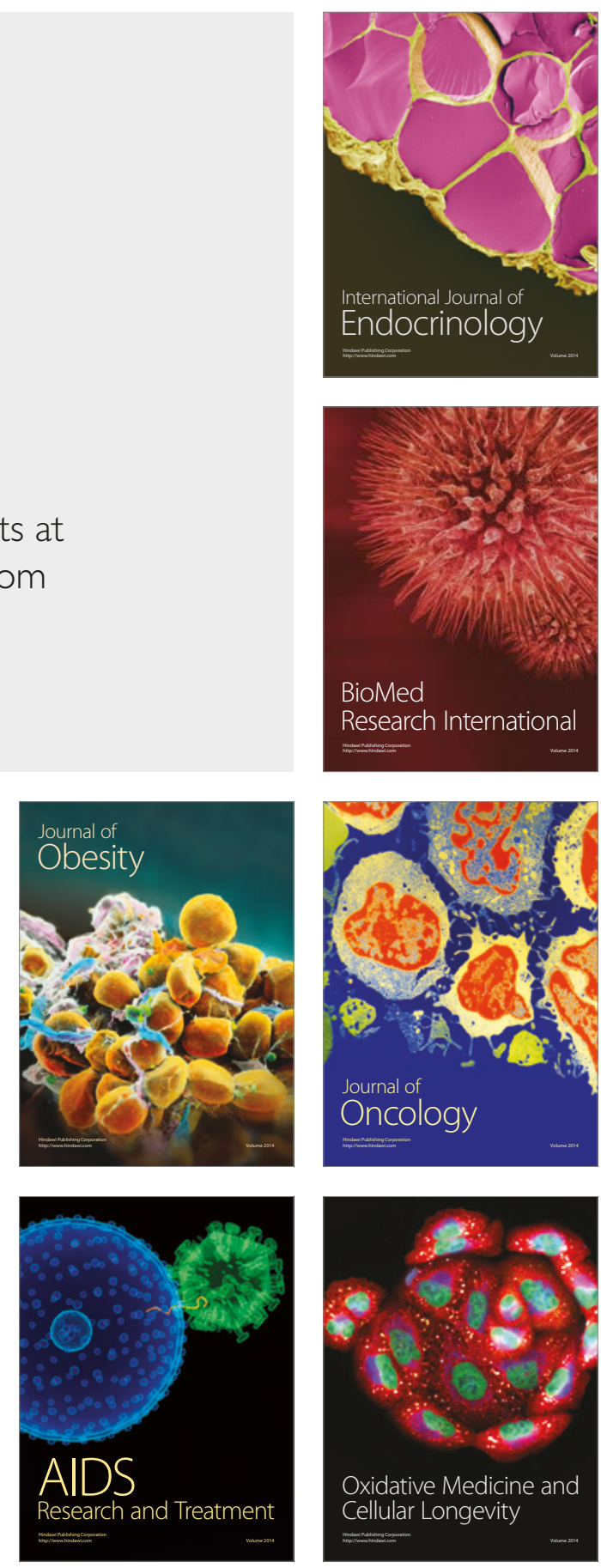